\title{
DECISION SUPPORT SYSTEM FOR VULNERABILITY ASSESSMENT OF MASONRY CHURCHES INCLUDING ARCHITECTURAL AND ARTISTIC ASSETS
}

\author{
V. SANGIORGIO ${ }^{1^{*}}$, G. UVA ${ }^{2}$ AND J. M. ADAM ${ }^{3}$ \\ ${ }^{1}$ DICATECh, Polytechnic of Bari, Via Edoardo Orabona, 4, 70126 Bari BA \\ E-mail: valentino.sangiorgio@poliba.it,webpage: \\ https://www.researchgate.net/profile/Valentino_Sangiorgio \\ ${ }^{2}$ DICATECh, Polytechnic of Bari, Via Edoardo Orabona, 4, 70126 Bari BA \\ E-mail: giuseppina.uva@poliba.it, \\ ${ }^{3}$ ICITECH Universitat Politècnica de València, Camí de Vera, s/n, 46022 València, Spagna \\ E-mail: joadmar@upv.es, webpage: http://www.upv.es/ficha-personal/joadmar
}

Keywords: Historical Structure, Masonry Churches, Non-Destructive Inspection, Failure Mechanisms, Macro-elements approach, Vulnerability Index, Architectural and Artistic Assets.

\begin{abstract}
The heritage building stock represents a significant element at risk from earthquakes, as recent seismic events have shown, especially in the Mediterranean area. In fact, in the last few years, the issue of assessing its seismic vulnerability has been widely discussed by the scientific community. The vulnerability assessment procedures involve many critical points related to the complexity and uncertainty of the parameters involved. If a detailed analysis of the individual buildings is to be performed this of course requires a great effort in both the data retrieval, modelling and analysis phases. In particular, historical masonry churches have been studied in detail in Italy and empirical approaches have been proposed in which a vulnerability index based on the classification of recurrent failure mechanisms is defined, exploiting a macro-elements approach to identify the parameters that influence the index. On the other hand, intangible aspects related to the architectural, historical and artistic value are not included in the Index, either in the structural parts themselves or in additional non-structural elements or contents. This paper proposes a procedure that combines the well-known vulnerability analysis based on the macro-elements approach and classification of recurrent failure mechanisms with an evaluation of the church's architectural and artistic assets, such as frescoes, statues and paintings, by applying the Analytic Hierarchy Process. The novel procedure is integrated in a useful Decision Support System to provide a complete overview of a church's structural condition, including its artworks, in order to create a priority scale for the assessment, retrofitting and protection of existing masonry churches.
\end{abstract}




\section{INTRODUCTION}

The masonry churches represent a significant building typology at risk from earthquakes, as recent seismic events have shown, especially in the Mediterranean area [1]. In fact, in the last few years, the issue of assessing its seismic vulnerability has been widely discussed by the scientific community. In the related literature, several multi-level procedures for the regional scale analysis of existing churches have been proposed [2,3]. In particular, historical masonry churches have been studied in detail in Italy and several empirical approaches have been developed to define a vulnerability index based on a macro-elements approach and exploiting the classification of recurrent failure mechanisms [4,5]. Such procedures involve a suitable onsite examination to identify damage, anti-seismic devices and vulnerability indicators. On the other hand, intangible aspects related to the architectural, historical and artistic value are not included in these approaches, either in the structural parts themselves or in additional nonstructural elements or contents.

This paper proposes a procedure to incorporate the potential losses (related to the artistic and architectural value of structural parts and additional artworks such as frescoes, statues and paintings) in the well-known vulnerability evaluation process of existing masonry churches. This methodology will provide a new "Index of artistic and architectural assets" through the application of the Analytic Hierarchy Process (AHP) [6]. Such multicriteria approach is particularly effective for the considered problem because it considers both quantitative and qualitative data in the analysis [7,8,9]. In addition, the resulting methodology can be implemented in a Decision Support System for a fast data acquisition. The resulting tool provide a complete overview of a church's structural condition, including its artworks, in orcer to create a priority scale for the assessment, retrofitting and protection of existing masonry churches. 2 OVERVIEW OF MACRO-ELEMENT APPROACH FOR ASSESSING CHURCH
VULNERABILITY

The Macro-Element analysed is based on the decomposition of a church in macro-elements in

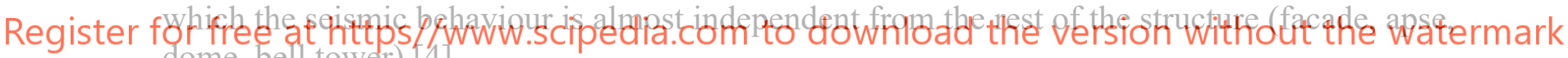
dome, bell tower) [4].

For each macro-element, the related collapse mechanism is evaluated through an on-site survey by considering the construction characteristics and quality (to provide an example the collapse mechanism "Façade Overturning" and "In Plane Mechanisms Of Façade" are belonging of macro-element of "Façade") [5].

In particular, a Vulnerability Index $i_{v}$, ranging between 0 and $1[10,11]$, is defined as a weighted average of the vulnerability of each macro-element ad it is defined as follows:

$$
i_{v}=\frac{1}{6} \frac{\sum_{k=1}^{28} \rho_{k}\left(v_{k i}-v_{k p}\right)}{\sum_{k=1}^{28} \rho_{k}}+\frac{1}{2}
$$

Where $\rho_{k}$ is assigned to the generic mechanism $k(1 \leq k \leq 28)$ that represents the influence of each mechanism on the overall behaviour of the structure (variable from 0.5 to 1 ). Moreover, $v_{k i}$ and $v_{k p}$ are respectively the vulnerability score and the anti-seismic score of the macroelement and are variable from 1 to 3 (during the survey the presence and of vulnerability elements such as thrusts of vaults, heavy elements, etc. or earthquake resistant elements such as tie rods and chains, buttresses, etc. is considered). 
In the present work, in order to consider intangible aspects of the architectural, historical and artistic value, an $i_{a}$, novel index, is defined by following in the footsteps of the simplified macro-element approach.

The Analytic Hierarchy Process [6] is applied to structure the problem and obtain tabulated values to determine $i_{a}$. This approach is able to take the artistic and architectural weighting of every church macro-element into account [5].

\section{AHP TO ANALYSE THE ARCHITECTURAL AND ARTISTIC ASSETS}

\subsection{First step of AHP: Definition of macro-criteria, criteria and alternatives}

The first step of the AHP consists in the decomposition of the problem structure in a flowchart. The purpose is to determine the tabulated weights useful for quantifying the potential losses in terms of artistic and architectural value. In particular the the goal of the flowchart is defined as the Artistic and architectural value quantification. Nine criteria $i$ (with $i=1, \ldots, 9$ ) are defined and grouped into three macro-criteria. For each criterion a set of alternatives $j$ (with $j=1, \ldots$, $\left.n_{i}\right)$ is defined to characterize the church, the macro elements and the related artistic asset. The nine criteria and related alternatives are structured in a hierarchical flowchart (see Figure 1) described below.

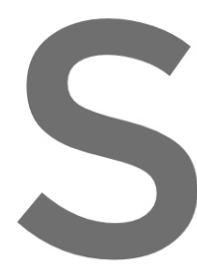

Goal

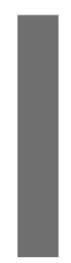

Macro-Criteria and Criteria

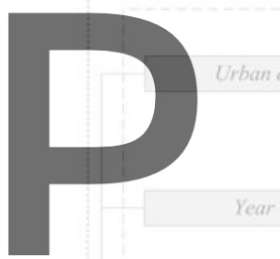

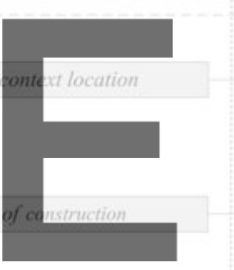

Alternative

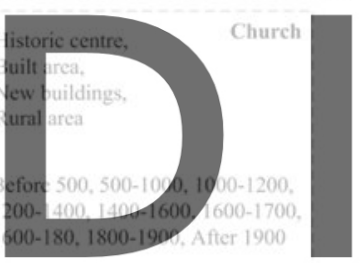

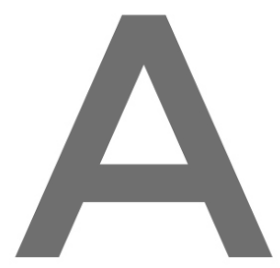

Register for free at https//www.scipedia.com to download the version without the watermark

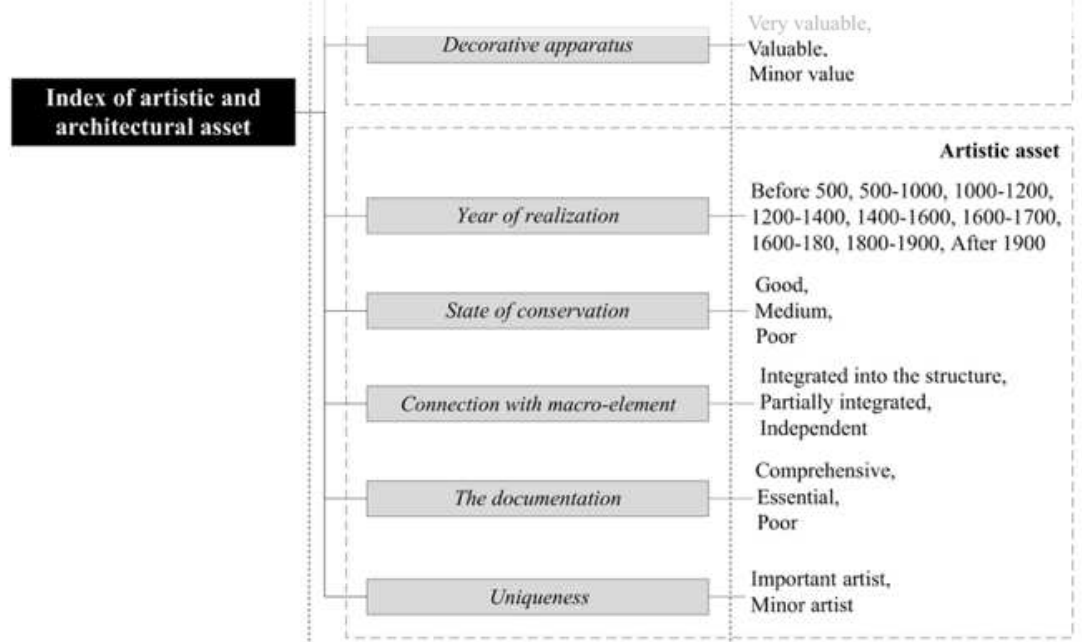

Figure 1: Structure of the problem in a flowchart: criteria and alternatives to determine an Index of artistic and architectural asset vulnerability. 
The First macro-criterion refers to the Church artistic and architectural value, in which the first two criteria are grouped together: 1) Urban context location to evaluate the importance of a structure in relation to their urban context [12]; 2) Year of construction to include value increasing connected to the antiquity [13].

The Second macro-criterion takes the characteristics of the church into account and contemplates two criteria: 3) Macro-element importance to consider the architectural value of the component and takes into account the contextualization of the asset [14]; 4) Decorative apparatus to evaluate the quantity and quality of the decoration of the macro-element, such as stuccos, pilasters, capitals, etc.

The Third macro-criterion considers the Artistic asset of every macro element, including any external and internal artistic heritage. This macro criterion includes the value of additional artwork such as frescoes, statues and paintings by five other criteria: 5) Year of creation because it influences the artistic asset, as in the case of architectural value [13]; 6) State of conservation that is directly connected with artistic value; 7) Likelihood of damage to contemplate the connection between the artistic asset and the Macro-element (some artistic assets such as frescos are closely connected to structural damage, while statues on the façade may be partially related to it, and some, such as an organ, can be completely independent of it); 8) Documentation to include the progress of studies that may have attributed different values to the asset over time [14]; 9) Uniqueness that is a fundamental qualitative parameter to take the existence of a masterpiece or a rare or invaluable art object into account[14].
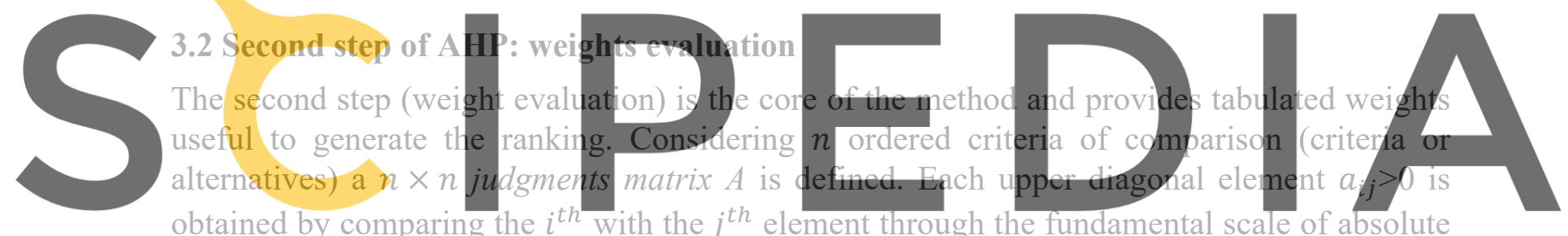
obtained by comparing the $i^{\text {th }}$ with the $j^{\text {th }}$ element through the fundamental scale of absolute

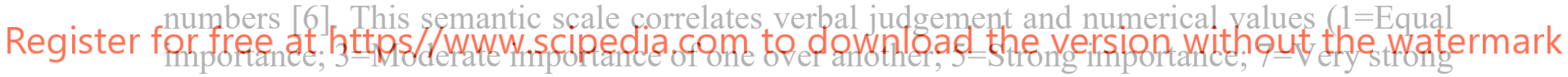
importance; 9=Extreme importance). The AHP uses the principal eigenvalue method to derive ratio scale priority vectors from judgments matrix $A$. In particular, weights are obtained by solving the following eigenvector problem:

$$
A w=\lambda_{\max } w
$$

where $w$ is the eigenvector and $\lambda_{\max }$ is the principal eigenvalue.

In particular, the criteria and alternative weights are defined as follows:

- $v_{i}$ is the weight associated with each $i^{\text {th }}$ criterion

- $w_{i j}$ is the weight associated with each $j^{\text {th }}$ alternative related to the $i^{\text {th }}$ criterion

This Section shows an example of how the literature on artistic and architectural assets can be exploited in order to obtain the judgment matrices $A$ and identify the weights $v_{i}$ and $w_{i j}$. For the sake of brevity, the weight calculations of the alternative related to Urban context location in the Church macro-criterion is shown. A qualitative analysis is carried out to obtain pairwise comparisons of the alternatives based on [12] and achieve the judgment matrix $A_{1}$. The weights are obtained by solving the eigenvector problem, as shown in Eq. (2) for matrix $A_{1}$. 
Table 1: Judgment Matrix $A_{1}$, weights, and CR obtained for the alternatives related to Urban context location.

\begin{tabular}{ccccccc}
\hline$A_{1}$ & (a) & (b) & (c) & (d) & $C R$ & $w_{l, j}$ \\
\hline Historic centre (a) & 1.0 & 5.0 & 8.0 & 3.0 & & 1.00 \\
Built-up area (b) & 0.2 & 1.0 & 2.0 & 0.7 & & 0.22 \\
New buildings (c) & 0.1 & 0.5 & 1.0 & 0.5 & 0.002 & 0.13 \\
Agricultural area (d) & 0.3 & 1.5 & 2.0 & 1.0 & & 0.30 \\
\hline
\end{tabular}

In the classical AHP approach [6] a suitable Consistency Ratio test $(C R<0.1)$ is used to verify the coherence of the resulting weights. In this example the $C R$ is equal to 0.002 and therefore the weights $w_{1 j}$ can be considered consistent (see Table 1).

After obtaining the weights of the intensity ranges related to each criterion, the second AHP step obtained the tabulated weights [5] related to the Structure of the Problem.

\subsection{Third step of AHP: global weight evaluation}

In the third and final step of the 'summary of priority' the global weights associated with each alternative are obtained by multiplying the criteria weight by the alternative weight, as in the classical AHP procedure:
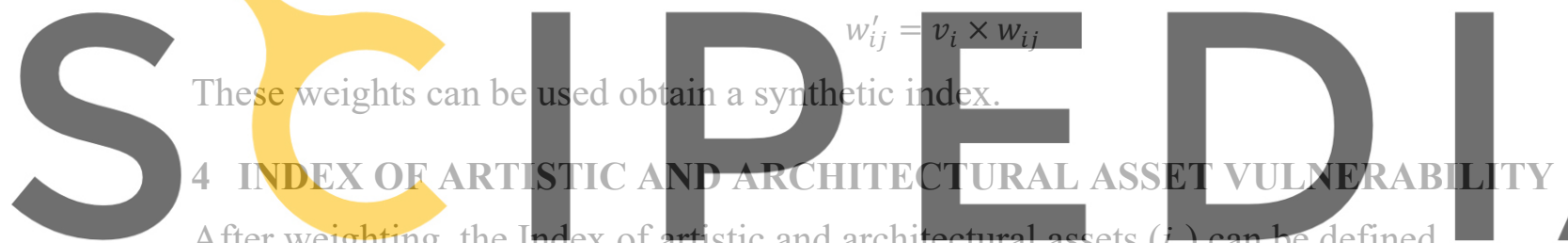

After weighting, the Index of artistic and architec

$i_{a}$ is assessed in relation to the 28 possible damage mechanisms of specific macro-elements.

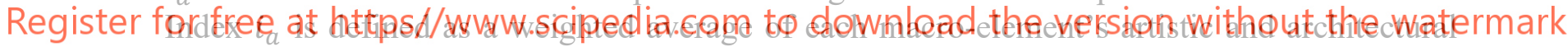
vulnerability:

$$
i_{a}=\frac{1}{6} \frac{\sum_{k=1}^{28} \alpha_{k}\left(v_{k i}-v_{k p}\right)}{\sum_{k=1}^{28} \alpha_{k}}+\frac{1}{2}
$$

Where, as in the classical procedure, $v_{k i}$ and $v_{k p}$ are respectively the seismic score and the antiseismic score of the macro-element (variable from 1 to 3) [4] and $\alpha_{k}$ is the artistic and architectural importance of the macro-element in relation to the damage mechanisms. This parameter is evaluated by using the obtained global weights as follows.

\subsection{The Artistic asset survey and $\alpha_{k}$ evaluation.}

$\alpha_{k}$ can be evaluated by means of a specific survey using the obtained AHP global weights. A suitable Survey form is proposed in order to identify and classify all the information and the alternatives associated with the church under study. An example of a Survey form is shown in Figure 2. The form is used to store information regarding the criteria of artistic and architectural importance and starts with information on its location. During the on-site survey, the Church, 
every macro element and the related architectural and artistic assets are evaluated by assigning an alternative in accordance with the AHP structuring of the problem.

The survey finishes after all the 28 damage mechanisms of the Macro-elements have been classified.

All the $j$ alternatives of the architectural and artistic asset are identified and stored for all the macro elements in a church. The weight $w_{i j}^{\prime}$ associated with every alternative can be obtained using the Tabulated weights [5] and Eq. (3), while $\alpha_{k}$ can be evaluated by the following equation:

$$
\alpha_{k}=\sum_{i=1}^{9} w_{i j}^{\prime}
$$

where $k$ is the considered mechanism and $w_{i j}^{\prime}$ is the global weight associated with the artistic assets of the macro element related to it.

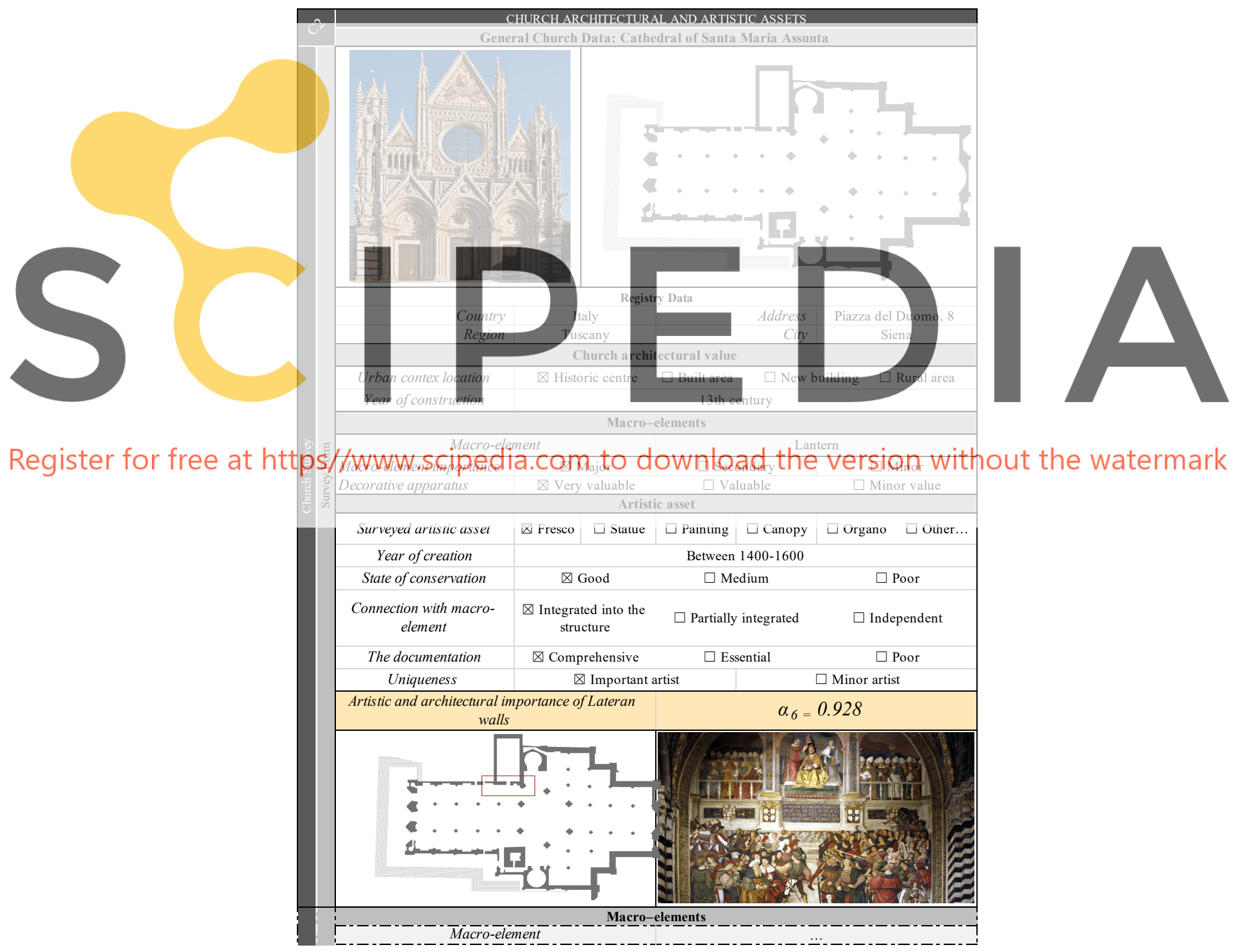

Figure 2: Extract from the Survey form of the Cathedral of Santa Maria Assunta: The "Libreria Silvio Picclomini" decorated by Pinturicchio. 
Note that $\alpha_{k}$ range between 0.25 and 1 and it can be useful to numerically evaluate the local artistic asset of every macro-element and also provides useful information on the church's global artistic and architectural assets. Indeed, its average value $\alpha_{\text {med }}$ (medium) can be evaluated by the following equation:

$$
\alpha_{\text {med }}=\sum_{k=1}^{28} \frac{\alpha_{k}}{k}
$$

Conclusively, $\alpha_{k}, \alpha_{\text {med }}$ and $i_{a}$ allow to evaluate numerically the local artistic asset of the single macro-element, the global artistic asset of the church and the global Vulnerability of the church respectively.

\section{THE INTEGRATION OF THE AHP-BASED APPROACH IN DSS}

The proposed approach can be easily exploited to set a spreadsheet useful to a rapid survey of an historical church [15]. In particular a suitable Survey form for a fast survey is develoned and a suitable flowchart is realized to better explain the DSS process.

\section{A. DSS Architecture}

The architecture of the proposed DSS is constituted by five components (Figure 3): i) A Data Management System (DMS) which collects the information provided by the users by the Survey form; ii) A Web-Based Platform, that represents the intelligence of the system. This platform processes the Survey form data, classifies the churches components and calculate the $\alpha_{k}, \alpha_{m e d}$

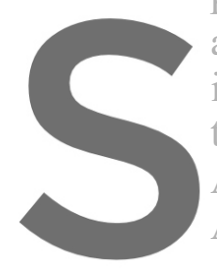
and finally the vulnerab implementable in a API the reported Survey for Application Programm Application with the We
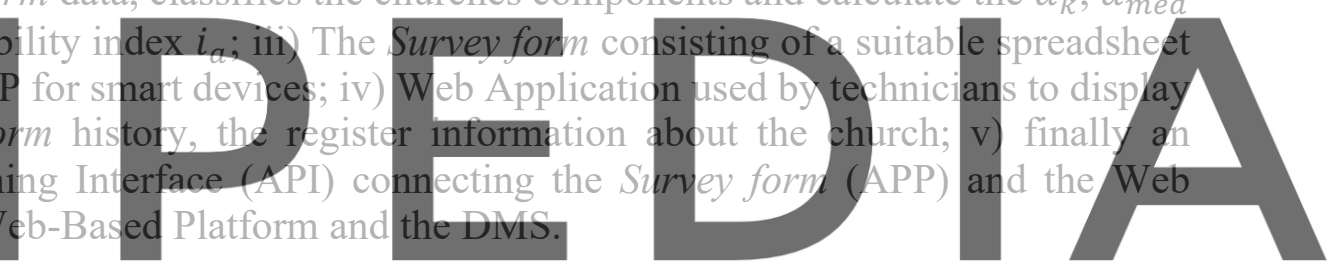

Register for free at https//www.scipedia.com to download the version without the watermark

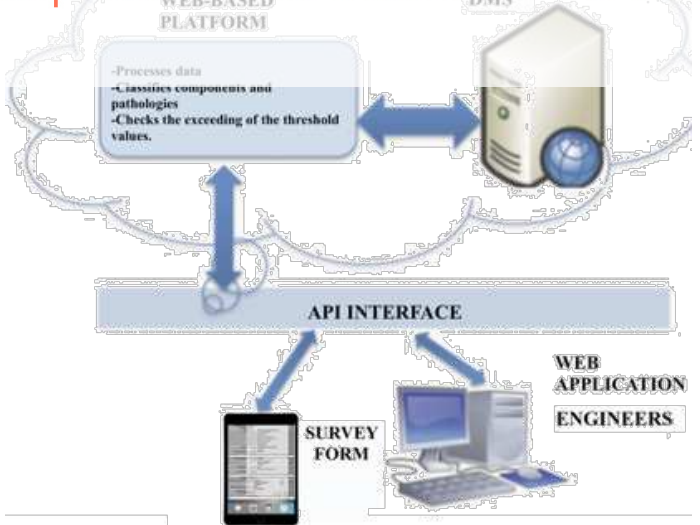

Figure 3: The generic matrix of judgments $\mathrm{A}$

\subsection{Survey form}

The core of the proposed approach is the definition of the Survey form implementable in an APP for smart devices. Such spreadsheet allows the user (technicians) to acquire data during a 
fast-visual inspection. The proposed APP can be used to perform the fast on-site survey by taking into account all the criteria and alternatives of the considered AHP problem.

\subsection{The DSS procedure}

In order to better specify the DSS procedure and the use of the Survey forms a suitable flowchart is realized in accordance with the UML framework (Figure 4). The rules and tasks of the actors involved in the process are pointed out.

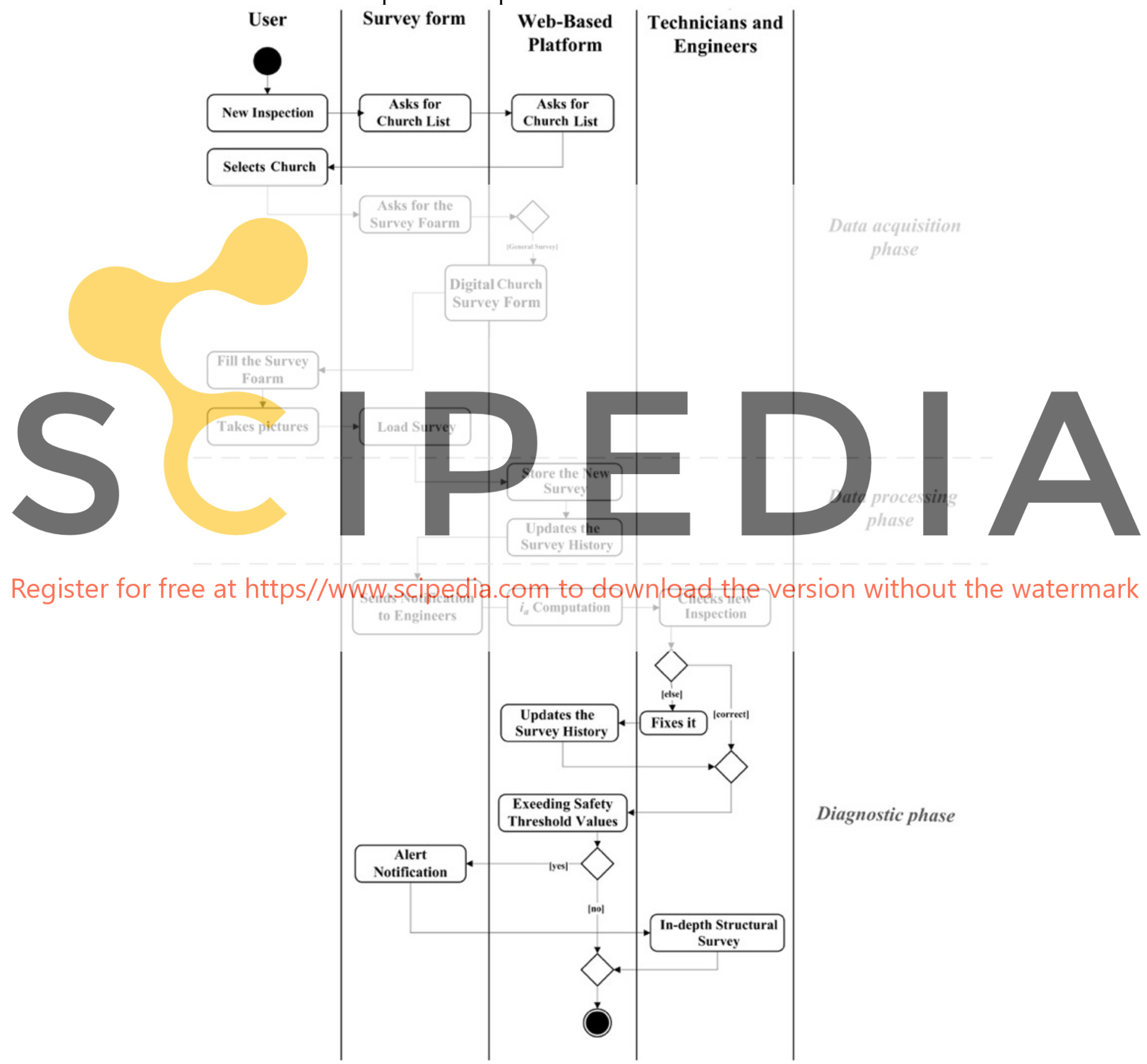

Figure 4: Flowchart to explain the procedure of the use of the System 
The flowchart procedure explains all the interactions between the two main components of the DSS, (i.e. Survey form implemented in smart devices and Web Application), and the actors involved in the process (i.e. Users of the Survey form and bridge technicians and engineers). The flow is described by defining three phases of the process: Data Acquisition Phase, Data Processing Phase and Diagnostic Phase.

i) During the Data Acquisition Phase, firstly, the user access to the churches list of the webbased platform to select the churches to survey. Secondly the user can ask to use the Survey form for the inspection. Thirdly the user can complete the inspection by taking photographs of vulnerability and earthquake resistant elements and sending the complete inspection to the Platform;

ii) in the Data Processing Phase, the Web Based Platform exploits the received surveys to store the new data and update the surveys history;

iii) finally, during Diagnostic Phase, the Web-Based Platform send new damages notification to the building staff that can read, change or validate the inspection. At this point, the System is able to automatically evaluate the vulnerability index, exploiting equation (3-4-5) and the tabulated weights obtained by the AHP. Finally, if the condition rating overcome some defined threshold values, a suitable the alarm protocol is triggered. An alert notification is sent to all users of the DSS to set up an emergency intervention.

\section{SITE TEST}

In order to test the proposed method, eight case studies were carried out in four cities in two European countries, Valencia (Spain) and Tuscany (Italy): i) the churches of San Agustín (13th
century), St. John (13th century) and San Juan del Hospital (13th century) in Valencia, ii) the
church of Santa Justa \& Rufina (14th dentury) and the Cathedral of Salvador (13th century) jn
Orihuela; iii) the Basilica of Santa Maria (17th century) in Elche; iv) and the Cathedral of Santa
Maria Assunta (13th dentury) and the Basilica of San Francesco (15th century) in Siena. These
churches are of different architectural styles, types of construction and different artistic churches are of different architectural styles, types of construction and different

for free at https//www.scipedia.com to download the version without the watermark 6.1 Church vulnerability analysis.

In the preliminary phase the existing information and documentation on the church design, modifications after construction and seismic history are collected. This information can be useful to identify some artistic and architectural assets or to verify the effectiveness of any vulnerability or earthquake-resistant elements.

After the preliminary phase, the on-site survey can be performed with the support of the Survey forms. For each church, every $k$ mechanism is analysed by assigning $v_{k i}$ and $v_{k p}$ in accordance with the classical method [4]. The Survey forms can then be filled in and the values of $\alpha_{k}$ can be identified by means of Eq. (5).

To provide an example, the 13th century Cathedral of Santa Maria Assunta is considered a masterpiece of Italian Gothic architecture. Both the exterior and the interior are built with white marble and green-and-black-striped marble, with the addition of red marble in the façade. The Cathedral is one of Italy's and the world's most valuable architectural assets, both for the materials used and the importance of the artists who decorated it. For example, Giovanni Pisano worked on the façade, Gian Lorenzo Bernini designed the lantern on the dome, Nicola Pisano created the pulpit of Carrara marble, many of the frescoes, paintings and stained glass were the work of Michelangelo, Donatello, Duccio di Buoninsegna and Cimabue. Another important 
macro-element is the chapel known as Libreria Piccolomini, with frescoes made by Pinturicchio on the drawings of Michelangelo (Figure 2). After the survey, the overall artistic value of the church was the highest of all those in the site test, with $\alpha_{\text {med }}=0.922$. However, except for some vulnerable elements such as the upper façade (due to the presence of a large rose window in addition to a high slenderness of the spire) and the many external statues, the quality of the masonry and some effective anti-seismic components (tie rods and buttresses) ensure a limited global vulnerability value of $i_{a}=0.599$.

\subsection{Site test results.}

The results showed that the most vulnerable churches are the Basilica of Santa María in Elche and the church of Santa Justa \& Rufina in Orihuela, due to their critical structural conditions in terms of seismic resistance and the importance of their artistic and architectural heritage. Antiseismic devices should be installed to improve their anti-seismic behaviour and avoid major damage. Figure 5 shows the façades of the churches and site test output.

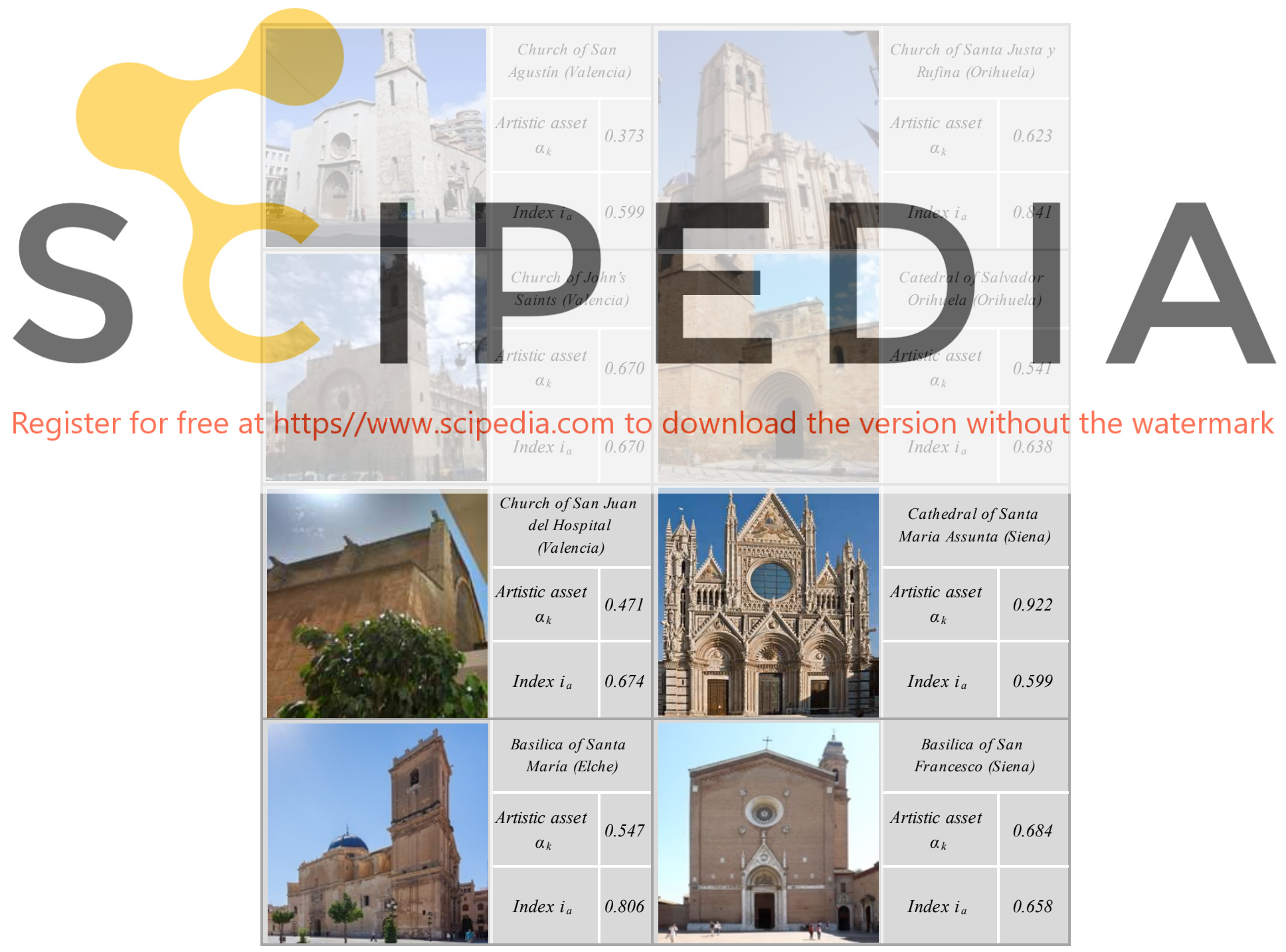

Figure 5: Façades of the churches and site test output. 


\section{CONCLUSIONS}

This paper proposes a novel procedure implementable in a Decision Support System to quantify masonry church vulnerability, including architectural and artistic assets in the analysis. This ambitious research has been carried out in four phases: i) the study of the existing macroelement approach and the related literature to identify the parameters that influence the architectural and artistic asses; ii) the application of the Analytic Hierarchy Process to quantify architectural and artistic assets and redefine the evaluation of the Index $i_{a}$; iii) the realization of Survey forms implemented in a DSS to support the data acquisition, and iv) the application of the method to a set of churches located in Valencia (Spain) and Tuscany (Italy) regions to prove potential of the novel approach.

The project involved a combination of interdisciplinary skills, including: structural engineering, forensic engineering, statistics, multi-criteria analysis and the evaluation of artistic assets. The results show the importance of providing a complete overview of a church's structural condition and its artistic assets in order to create a priority scale for the assessment, retrofitting and protection of existing masonry churches. The DSS is a powerful and easy-to-apply tool and includes important information on potential artistic losses during a seismic event.

Further research will be carried out to apply the novel Decision Support Systems at a largescale.

\section{REFERENCES}

[1] Canuti, C., S. Carbonari, A. Dall'Asta, L. Dezi, F. Gara, G. Leoni, M. Morici, E. Petrucci, A. Prota, and A. Zona. 2019. Post- earthquake damage and vulnerability assessment of churches in the Marche Region struck by the 2016 central Italy seismic sequence. International Journal of Architectural Heritage 1-22. doi:10.1080/15583058.2019.1653403.

[2] Sangiorgio, V., G. Uva, and F. Fatiguso. 2018. User-reporting based semeiotic assessment of existing building stock at the regional scale. Journal of Performance of Constructed Facilities 32 (6):04018079. doi:10.1061/(ASCE)CF.1943- 5509.0001227.

[3] Sangiorgio, V., G. Uva, F. Fatiguso, and J. M. Adam. 2019. A new index to evaluate exposure and potential damage to RC building structures in coastal areas. Engineering Failure Analysis 100:439-55. doi:10.1016/j.engfailanal.2019.02.052.

[4] Lagomarsino, S., S. Podestà, G. Cifani, and A. Lemme. 2004. The 31st October 2002 earthquake in Molise (Italy): A new methodology for the damage and seismic vulnerability survey of churches. Proceeding of the 13th World Conference on Earthquake Engineering Vancouver, B.C., Canada, August 1-6.

[5] Sangiorgio, V., Uva, G., and Adam, J. M. 2020. Integrated Seismic Vulnerability Assessment of Historical Masonry Churches Including Architectural and Artistic Assets Based on Macro-element Approach. International Journal of Architectural Heritage, 114. doi: 10.1080/15583058.2019.1709916.

[6] Saaty, T. L. (2008). Decision making with the analytic hierarchy process. International journal of services sciences, 1(1), 83-98.

[7] Sangiorgio, V., G. Uva, and F. Fatiguso. 2017. Optimized AHP to overcome limits in weight calculation: A building perfor- mance application. Journal of Construction Engineering and Management. doi:10.1061/(ASCE)CO.1943-7862.0001418. 
[8] Uva, G., Sangiorgio, V., Ruggieri, S., \& Fatiguso, F. (2019). Structural vulnerability assessment of masonry churches supported by user-reported data and modern Internet of Things (IoT). Measurement, 131, 183-192.

[9] Sangiorgio, V., Uva, G., \& Fatiguso, F. (2016). A procedure to assess the criticalities of structures built in absence of earthquake resistant criteria. REHABEND, 2016, 631-639.

[10] De Matteis, G., E. Criber, and G. Brando. 2016. Damage probability matrices for threenave masonry churches in Abruzzi after the 2009 L'Aquila earthquake. International Journal of Architectural Heritage 10 (2-3):120-45.

[11] De Matteis, G., G. Brando, and V. Corlito. 2019a. Predictive model for seismic vulnerability assessment of churches based on the 2009 L'Aquila earthquake. Bulletin of Earthquake Engineering 17 (9):4909-36. doi:10.1007/s10518-019-00656-7.

[12] Jokilehto, J. 2006. World heritage: Defining the outstanding universal value. City and Time $2(2): 1$.

[13] İpekoğlu, B. 2006. An architectural evaluation method for con- servation of traditional dwellings. Building and Environment 41 (3):386-94. doi:10.1016/j.buildenv.2005.02.009.

[14] Ghizzi, S. 1994. Aspetti economici del restauro archeolgoico, in Note di Economia dei Beni Culturali ed Ambientali. Rivista di Analisi dei Problemi di Finanziamento, Valutazione e Gestione dei Progetti di Investimento per il Restauro e la Valorizzazione dei Beni Culturali, Anno II, Numero 1, Roma. doi:10.3168/jds.S0022-0302(94)77044-2.

[15] Sangiorgio, V., Martiradonna, S., Uva, G., \& Fatiguso, F. (2017, September). An information system for masonry building monitoring. In 2017 IEEE International Conference on Service Operations and Logistics, and Informatics (SOLI) (pp. 230-235). IEEE. 